\title{
Cell Therapy With Human ESC-Derived Cardiac Cells: Clinical Perspectives
}

\author{
Philippe Menasché1,2* \\ ${ }^{1}$ Department of Cardiovascular Surgery, Hôpital Européen Georges Pompidou, Paris, France, ${ }^{2}$ PARCC, INSERM, University \\ of Paris, Paris, France
}

OPEN ACCESS

Edited by:

Martijn van Griensven,

Maastricht University, Netherlands

Reviewed by:

Hidetoshi Masumoto,

RIKEN Center for Biosystems Dynamics Research (BDR), Japan

Richard Lee,

Harvard University, United States

Jop Van Berlo,

University of Minnesota Twin Cities,

United States

*Correspondence:

Philippe Menasché

philippe.menasche@aphp.fr

Specialty section:

This article was submitted to Tissue Engineering and Regenerative

Medicine,

a section of the journal

Frontiers in Bioengineering and

Biotechnology

Received: 01 September 2020 Accepted: 02 October 2020

Published: 26 October 2020

Citation:

Menasché P (2020) Cell Therapy With Human ESC-Derived Cardiac

Cells: Clinical Perspectives.

Front. Bioeng. Biotechnol. 8:601560.

doi: 10.3389/fbioe.2020.601560
In the ongoing quest for the "ideal" cell type for heart repair, pluripotent stem cells (PSC) derived from either embryonic or reprogrammed somatic cells have emerged as attractive candidates because of their unique ability to give rise to lineage-specific cells and to transplant them at the desired stage of differentiation. The technical obstacles which have initially hindered their clinical use have now been largely overcome and several trials are under way which encompass several different diseases, including heart failure. So far, there have been no safety warning but it is still too early to draw definite conclusions regarding efficacy. In parallel, mechanistic studies suggest that the primary objective of "remuscularizing" the heart with PSC-derived cardiac cells can be challenged by their alternate use as ex vivo sources of a biologically active extracellular vesicle-enriched secretome equally able to improve heart function through harnessing endogenous repair pathways. The exclusive use of this secretome would combine the advantages of a large-scale production more akin to that of a biological medication, the likely avoidance of cell-associated immune and tumorigenicity risks and the possibility of intravenous infusions compatible with repeated dosing.

Keywords: embryonic stem cell, cardiac cell, heart failure, ischemic heart, induced pluripoten stem cell

\section{WHY PLURIPOTENT STEM CELLS?}

\section{Rationale for the Use of Cardiac-Committed Cells}

So far, it is fair to acknowledge that no one can claim that a given cell type has unequivocally demonstrated its superiority over another for inducing heart repair and the attendant improvement in left ventricular function. Nevertheless, the few comparative experimental studies which have been published suggest the interest of using cells which are phenotypically matched to those of the organ to be repaired and thus highlight the potential benefits of cardiac-committed cells. A first comparison of human induced pluripotent stem cell (iPSC)-derived cardiomyocytes versus human mesenchymal stromal cells (MSC) injected 30 min after permanent coronary artery ligation in rats reported that the former tended to improve left ventricular function to a greater extent and significantly reduced fibrosis compared with MSC (Citro et al., 2014). In a subsequent head-to-head comparison of different human stem cell types, cardiosphere-derived cells were found superior to MSC from bone marrow and adipose tissue and to bone marrow-derived mononuclear cells (BMMNCs) for improving post-infarction cardiac function and cell engraftment in a mouse model also treated just after ligation of the left anterior descending artery (Li et al., 2012). Likewise, human embryonic stem cell (ESC)-derived cardiomyocytes and mesodermal cardiovascular progenitors were found to similarly improve post-infarction systolic function in contrast to BMMNCs in rat 
hearts treated 4 days after a $60 \mathrm{~min}$ period of coronary artery occlusion (Fernandes et al., 2015). In keeping with these data, the more recent pig study of Ishida et al. (2019) shows that in comparison of skeletal myoblasts and MSC, iPSC-derived cardiomyocytes (all cells being of human origin) yielded the best outcomes with regard to regional function, oxidative metabolism, vascular density and limitation of apoptosis. However, an opposite conclusion emerged from another comparative study of iPS derivatives where MSC were found superior to cardiomyocytes for the improvement of cardiac function in heart failure, an effect primarily attributed to their immunomodulatory effects (Liao et al., 2019). This discrepancy could be related to very specific features of this protocol: the induction of heart failure by coronary artery occlusion associated with rapid pacing, a setting known for its instability and the intensity of neuro-hormonal stimulation (Yarbrough, 2003); the use of different PSC sources (ESC for cardiomyocytes and iPSC for MSC); the application of a uniform immunosuppression regimen to MSC and cardiomyocytes whereas the former are known to be more immune evasive, which was indeed reflected in that study by their lower expression of Human Leukocyte Antigen (HLA)-II; the greater susceptibility of ESCderived cardiomyocytes to an immune response could thus have accounted for their lower rate of survival and their (slightly) inferior functional performance. In brief, these data are difficult to interpret because of all these confounders and do not challenge the concept that an optimal therapeutic benefit likely requires that both transplanted and host cells belong to the same lineage.

In practice, adult tissue sources of cardiac cells are limited to cardiospheres and $\mathrm{c}-\mathrm{kit}^{+}$cardiac stem cells (CSC) whose harvest from heart tissue does not equate to their cardiac lineage commitment. Cardiospheres are agglomerates of several cell types, predominantly MSC, harvested from the right ventricle by an endomyocardial biopsy (Smith et al., 2007) with a subsequent intracoronary delivery while c-kit ${ }^{+}$CSC are grown from a right appendage biopsy taken during a coronary artery bypass operation before being also reinjected into the coronary arteries. However, the first have failed to show benefits in an ischemic cardiomyopathy phase II trial which was prematurely interrupted in April, 2017 for futility; however, the use of these cells in Duchenne muscular dystrophy has yielded an encouraging efficacy signal (Taylor et al., 2019) which needs to be confirmed by the ongoing HOPE-II study, planned to randomize 84 non-ambulatory and ambulatory patients with Duchenne muscular dystrophy to intravenous infusions of either 150 million cardiosphere-derived cells every 3 months for a total of 4 doses or placebo. The use of $c-k i t^{+}$CSC has been largely based on preclinical data now considered to be in part fraudulent ${ }^{1}$ and there is some consensus that these cells are rather endowed with an angiogenic potential (van Berlo et al., 2014). Four trials are currently registered in the ClinicalTrials.gov website, of which one (CONCERT-HF) which has tested transendocardial injections of autologous MSC, c$\mathrm{kit}^{+}$CSC, alone or in combination, in patients with ischemic heart failure, was temporarily paused in October, 2018. Among

${ }^{1}$ News at a glance. Science 362, 268-270. doi: 10.1126/science.362.6412.268 the remaining 3 studies, only one, the CHILD trial, which assesses the effects of intramyocardial injection of autologous c$\mathrm{kit}^{+}$cells in 32 patients with hypoplastic left heart syndrome, is currently recruiting. A second one (TAC-HF-II) planned to test transendocardial injection of autologous MSC alone or in combination with CSC in 55 patients with ischemic left ventricular dysfunction, has not yet started recruiting. The third trial (JOKER) was designed to assess the effects an intracoronary infusion of autologous $\mathrm{c}-\mathrm{kit}^{+}$cells expanded from a right appendage biopsy taken during coronary surgery in a small group of six patients still presenting a left ventricular ejection fraction $<40 \%$ after their revascularization; it is reported active but not recruiting. Outcomes of these trials will hopefully shed some light on the place of these cells in the context of cellbased heart repair.

\section{Interest of PSC as a Source of Cardiac-Committed Cells}

Given the limitations of these adult sources of cardiac-committed cells, it has looked sound to consider the alternate use of pluripotent stem cells (PSC) to leverage their intrinsic ability to generate lineage-specific cells in response to appropriate cues and thus coax them toward a cardiac differentiation pathway. Since the seminal work of Caspi et al. (2007) showing that ESCderived cardiomyocytes improved myocardial performance in chronically infarcted rats, a flurry of studies have confirmed the functional efficacy of PSC cardiac derivatives. This has been a strong incentive for developing multiple and various techniques for PSC scale-up and differentiation, the detailed description of which is beyond the scope of this article (for a recent review, see Le and Hasegawa, 2019). Enough is to say that the extensive documentation on the raw products required for a regulatory approval makes highly desirable to use the most straightforward and cost-effective procedures, which has guided our choice of an only two cytokine-based technique described below. Another advantage of PSC is their scalability which is critical particularly if the objective is the "remuscularization" of extensively scarred post-infarction myocardial areas (as discussed below). One could argue that this property is shared by MSC but it is not totally true as there is some evidence that increasing the number of MSC passages can shift their phenotype toward an aging pattern translating into an impaired functionality of the cells (Yin et al., 2019).

The ability to control the differentiation pathway of PSC gives the flexibility of "freezing" it at the desired stage and thus provides the option of transplanting early progenitor cells or more mature cardiomyocytes. Each of these cell types has advantages and inconvenient. Early progenitors feature a greater plasticity which could allow them to differentiate in both cardiac and vascular cells and their predominant reliance on anaerobic glycolysis might enhance their survival in a poorly oxygenated environment. This assumption is supported by the findings of Halbach et al. (2014) that the highest persistence and grade of electrical coupling of intramyocardially transplanted fetal cardiomyocytes from different developmental stages is achieved by intermediate cells (days 14.5) compared with earlier and later 
stages (days 9.5 and 18.5, respectively). An additional feature of early progenitor cells is their greater secretory profile (Agarwal et al., 2017; El Harane et al., 2018), which can be an advantage if one relies on a predominant paracrine mechanism of action (see below). At the opposite, an early progenitor cell population can still be "contaminated" by pacemaker cells behaving as foci of automaticity and thus predisposing to arrhythmias (Ichimura et al., 2020). Conversely, this issue is addressed by the use of more mature cardiomyocytes which are thought to be endowed with a greater force-generating potential but, in turn, may be more susceptible to death once transplanted in hypovascularized areas because of their reliance on oxidative phosphorylation. At the end, it is fair to admit that currently the few studies which have compared different stage-specific cardiac differentiated cells have failed to provide unequivocal evidence for the superiority of one type over the other (Fernandes et al., 2015; Ye et al., 2015).

\section{The ESCORT Trial}

Our choice has been to transplant early progenitors differentiated from ESC in the ESCORT trial (NCT02057900) which was a first-in-man safety study of 6 patients with severe ischemic left ventricular dysfunction (median left ventricular ejection fraction: 26\%; IQR: $22-32 \%$ ) and in whom the cell therapy treatment was combined with a coronary artery bypass (Menasché et al., 2018). The trial was based on 10 years of preclinical studies in rodents and non-human primates (Bellamy et al., 2015; Menasché et al., 2015). Pluripotent ESC were first scaled-up to generate a master/working cell bank from which cells were collected, thawed, expanded in a defined medium on clinical-grade feeder cells (irradiated human foreskin fibroblasts) and then committed toward a mesodermal-cardiac lineage by a 4-day exposure to two cytokines (bone morphogenetic protein-2 and a FGF inhibitor) according to Good Manufacturing Practice (GMP) standards. As roughly $44 \%$ of the cells only responded to the cardio-instructive cues, a purification step was mandatory. The expression of stage-specific embryonic antigen (SSEA)-1, was then taken as a marker for loss of pluripotency and immunomagnetic sorting using a microbead-coupled anti-SSEA-1 antibody was used for selecting the committed cells. This resulted in the harvest of a highly purified population of SSEA- $1^{+}$cells characterized by a knock-down of the pluripotency gene Nanog and a parallel upregulation of the cardiac transcription factor Isl-1. These two markers, assessed by qPCR, were among the release criteria, with thresholds set as $<0.1 \%$ and $>5 \%$, respectively, expressed as fold changes relative to the undifferentiated population. Additional lot release criteria included cell viability and purity, with thresholds set at 90 and 95\%, respectively, which were fully met for all the patients [median viability and purity rates of 96\% (IQR: 96-96\%) and 97.5\% (IQR: 95.5-98.7\%), respectively]. SSEA$1^{+}$progenitor cells were then embedded into a fibrin patch generated by first mixing them with fibrinogen followed by addition of thrombin to induce rapid polymerization of the gel (fibrinogen and thrombin were components of a clinically used surgical glue). Finally, during the surgical procedure, a $20 \mathrm{~cm}^{2}$ piece of autologous pericardium was harvested and sutured to the epicardium along one-half the borders of the infarct area, thereby creating a pocket into which the cell-loaded fibrin patch was simply slipped. The free edge of the pericardial flap was then stitched to the remaining half of the infarct circumference, thereby enclosing the fibrin patch and ensuring its stability. The use of the pericardium was based on the assumption that it could act as a natural bioreactor providing growth factors to the underlying cellular graft and thus contributing to enhance early cell survival (Figures 1, 2). A median dose of SSEA-1 ${ }^{+} I s l$ 1 cardiovascular progenitors of 8.2 million (IQR: 5-10 million) was delivered without any adverse intraoperative events. The primary end point was safety at 1 year, primarily assessed on (1) cardiac teratoma or remote tumor tracked by whole body computed tomography and fluorine-18 deoxyglucose positron emission tomography scans, (2) arrhythmias, detected by serial interrogations of the cardioverter-defibrillator implanted in all patients, and (3) alloimmunization, assessed by the presence of donor-specific antibodies. All patients had an uneventful post-operative course, except for one who died shortly after the operation from multiple comorbidities. With a maximum follow-up of 6 years, no patient presented an adverse event that could be related to the cells and/or the patch. While it would be meaningless to draw conclusions regarding efficacy, enough is to say that an encouraging signal was provided by a significant improvement of the wall motion of the cell/patchtreated segments during follow-up with a score that decreased from $4.2 \pm 0.8$ at baseline to $2.5 \pm 0.4$ at 1 year $(p=0.004$ by the mixed model ANOVA on ranks). Of note, in 3 of the 4 patients who contributed these 1-year data, the treated segments had not been revascularized but, again, this cannot be taken as definite proof of efficacy because of the confounding effect of concomitant revascularization. Since we were not expecting a long-term cellular engraftment and primarily relied on a paracrine mechanism of action (see below), patients were only immunosuppressed transiently and while the initial planning was to give the drugs for 2 months, the duration was shortened to 1 month from the second patient onward. Drugs were given at a relatively low dosing (target trough levels of cyclosporine: 100-150 ng/ml; mycophenolate mofetil, 2 g/day) since our preoperative mixed lymphocyte reaction assays had shown that SSEA- $1^{+}$cells are weakly immunogenic.

\section{Other PSC Clinical Trials}

Other investigators have made the different choice of transplanting PSC-derived cardiomyocytes at a later stage of differentiation (although their persistent fetal-like phenotype precludes their assimilation to bona fide myocardium-resident cardiomyocytes) and have switched to iPSC as the source cells for practicality and/or ethical reasons. Once differentiated, iPSC-derived cardiomyocytes share with ESC the ability to improve the function of infarcted hearts (Lee et al., 2017) but also the lack of long term engraftment (Okano and Shiba, 2019). The use of iPSC has been aggressively promoted by those who oppose ESC for religious reasons with the premise that they could be differentiated from the patient's own somatic cells, thereby obviating the use of immunosuppression. This argument is no longer tenable since there is a consensus that iPSC for clinical purposes should rather be harvested from healthy donors, i.e., in an allogeneic mode, to improve safety and potency and decrease costs. This is actually the case for two trials in patients with ischemic heart failure: one in Japan aims 


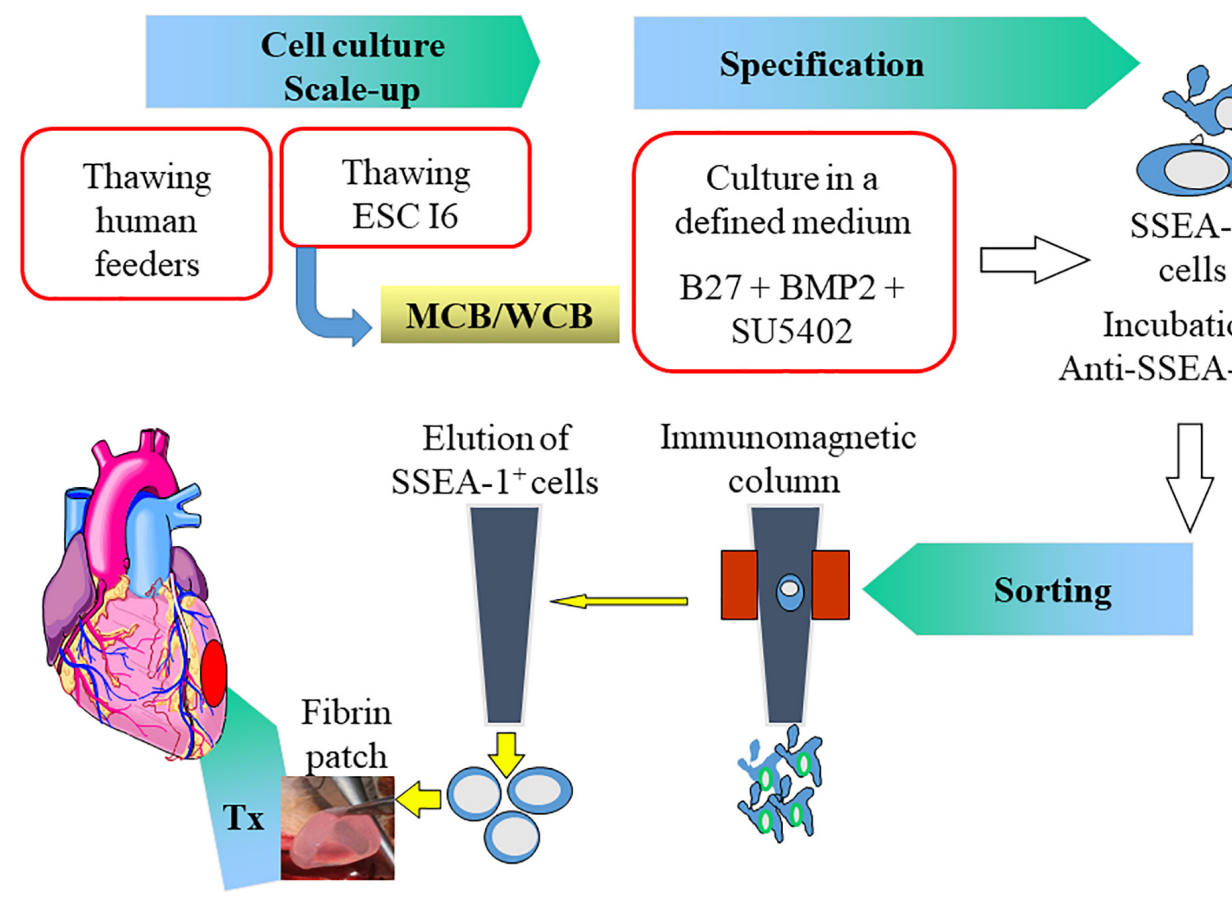

FIGURE 1 | Summary of the protocol in the ESCORT trial. Human Embryonic Stem Cells (ESC) from the 16 cell line were expanded on human feeders to generate a Master/Working Cell Bank (MCB/WCB). Expanded pluripotent stem cells (scale-up) were then cardiac-committed (specification) by a 4-day exposure to Bone Morphogenetic Protein (BMP)-2 and a Fibroblast Growth Factor inhibitor (SU5402) in B27 medium. Committed cells express the Stage-Specific Embryonic Antigen (SSEA)-1 indicating their loss of pluripotency and could thus be immune-magnetically sorted using an anti SSEA-1 antibody. The SSEA-1 enriched cardiovascular progenitor cell population was then embedded in a fibrin patch which was transplanted onto the epicardium of the infarct area. AB: antibody; Tx: transplantation.

at grafting allogeneic iPSC-derived cardiomyocytes in 10 patients with a severe cardiomyopathy under the form of cell sheets prepared according to a well-documented technology (Guo et al., 2020). The announcement of the first operation in this series has been made in the lay press in January, $2020^{2}$, but at the time of this writing, this trial is not registered on University Hospital Medical Information Network (UMIN CTR), Japan ${ }^{3}$ and only its 3-patient roll-in phase is listed as terminated (UMIN000032989). The second trial which is in preparation in Germany plans to graft engineered heart constructs (Tiburcy et al., 2017) made of iPSC-derived cardiomyocytes and collagen in patients with end-stage heart failure. Of note, in these two studies, cell therapy will be used as a stand-alone procedure which will allow a true assessment of its effects without the confounding effect of an associated procedure and also makes possible a less invasive approach by a small left thoracotomy. Conversely, another trial (HEAL-CHF, NCT03763136), in China, should include five participants with ejection fractions between 30 and $45 \%$ who will be injected intramyocardially with 100 million allogeneic iPSC-derived cardiomyocytes but in conjunction with coronary artery bypass grafting. This study is currently recruiting. A last trial planned to include 3 patients with chronic heart failure and in whom autologous iPSC-derived cardiomyocytes would be

\footnotetext{
${ }^{2}$ https://www.japantimes.co.jp/news/2020/01/28/national/science-health/osakauniversity-transplants-ips-cell-based-heart-cells-worlds-first-clinical-trial/

${ }^{3}$ https://www.umin.ac.jp/ctr/
}

delivered intravenously has been registered in ClinicalTrials.gov in November 2018 (NCT03759405) but has surprisingly not yet started recruiting.

\section{The Issue of Dosing}

A critically relevant issue raised by transplantation of PSCderived cardiomyocytes, regardless of their ESC or iPSC source, is their optimal dosing. Several factors have to be taken into account, including the mass of lost myocardium, particularly if the objective is its remuscularization (as discussed below), the rate of cell attrition and the possible proliferation of the surviving cells although the latter factor is of unlikely clinical relevance because of the consistent finding of the absence of sustained cell engraftment. In a meta-analysis of stem cells in large animal studies (primarily performed in pigs), cells doses were extremely variable, ranging from $5 \times 10^{5}$ to $25 \times 10^{6}$ for c-kit CSC, from $1.3 \times 10^{6}$ to $1 \times 10^{7}$ for cardiospheres and also averaged $1 \times 10^{7}$ for Sca-1 + CSC. Interestingly, in the only dose-escalating study of cardiospheres (Yee et al., 2014), the highest dose (150 million) was found superior to the lower ones when the assessment was made 4 weeks after treatment but the benefit on global and regional left ventricular function (versus a control group) was lost in a subsequent cohort receiving this high dose but assessed at a later time point (8 weeks). In a Phase II dose-escalation study of allogeneic mesenchymal precursor cells in patients with ischemic or non-ischemic heart failure (Perin et al., 2015), the best outcomes were yielded by 

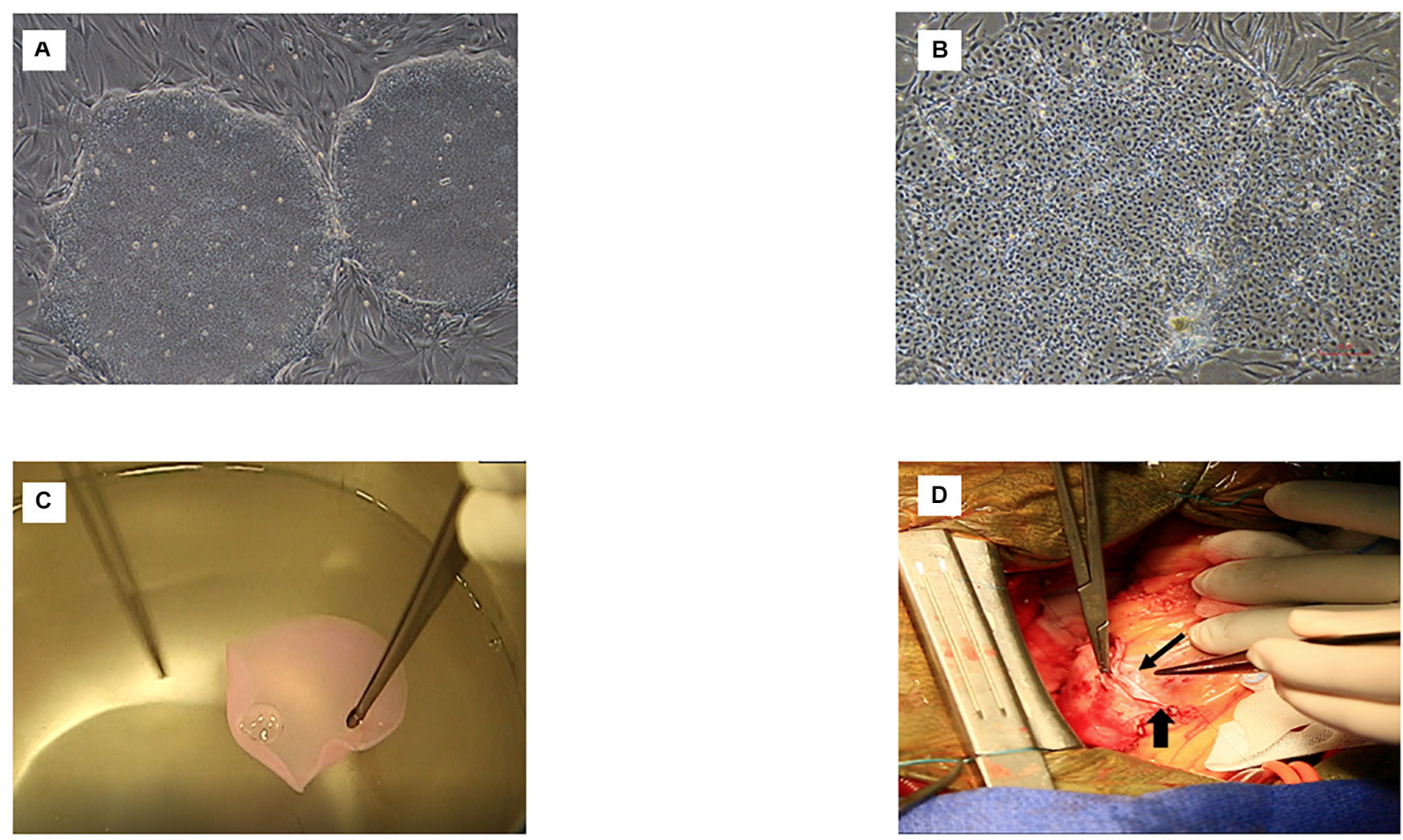

FIGURE 2 | Main steps of the procedure in the ESCORT trial. (A) Pluripotent ESC of the 16 cell line. (B) Cardiovascular progenitors at the completion of the 4-day specification step. (C) Fibrin patch loaded with the cardiovascular progenitors (intra-operative picture showing the rinsing of the patch before its implantation in the patient). (D) Final step: the cell-loaded patch has been delivered onto the epicardium of the infarct area and is partly covered by a pericardial flap already sutured along one-half the infarct circumference, thereby creating a pocket (between the flap and the epicardium) inside which the patch has been slid; the long and thin arrow indicates the border of the patch. The short and wider arrow indicates the suture line of the pericardial flap to the epicardium. Once the cell-loaded fibrin patch seats within the pocket, this suture line will be completed along the remaining one-half of the infarct circumference to enclose it completely, thereby ensuring its stability while providing some trophic support to the underlying fibrin patch.

the highest dose (150 million versus 25 and 75 million) and a similar dose-dependent response (better with 100 versus 20 million cells) has been reported in the TRIDENT trial in which allogeneic bone marrow-derived-MSC were delivered in patients with ischemic cardiomyopathy (Florea et al., 2017). These data are consistent with those of a metaanalysis of 914 MSC clinical trials (for all types of indications) in which the minimal effective dose ranged between 100 and 150 million cells (Kabat et al., 2020). Admittedly, however, none of these clinical studies have used PSC derivatives. Looking exclusively at those transplanted in nonhuman primate models generates conflicting results. Chong et al. (2014) reported an extensive remuscularization of the infarcted myocardium injected with $1 \times 10^{9}$ ESC-derived cardiomyocytes but the small sample size precluded any meaningful functional assessment. Conversely, despite injecting a similar cell number, Romagnuolo et al. (2019) failed to show a benefit on infarct size or global left ventricular function (with no correlation between cardiomyocyte purity and graft size) after 4 weeks. In contrast, Liu Y.-W. et al. (2018) reported a functional benefit following transplantation of a slightly lower dose $\left(7.5 \times 10^{8}\right)$ of ESCderived cardiomyocytes and in the study of Shiba et al. (2016), a post-transplantation improvement of contractile function at 4 and 12 weeks could even be yielded by an almost twofold lower dose dose $\left(4 \times 10^{8}\right.$ iPSC-derived cardiomyocytes $)$. Finally, in another study using ESC-derived cardiovascular progenitors, a much lower dose $\left(1 \times 10^{7}\right)$ also improved heart function provided the immunosuppression regimen was appropriate (Zhu et al., 2018). Put together, these data suggest that the highest doses are not necessarily the most effective, particularly in view of the risk of arrhythmias outlined in the next section, and although the issue of the optimal dosing is still open, they tend to support the earlier experimental findings that even though increasing the dose of ESC translates into an increased graft size, this may not reflected by an improvement in heart function (van Laake et al., 2009).

\section{HOW DO PSC-DERIVED CARDIAC CELLS WORK?}

\section{The "Remuscularization" Hypothesis}

A logical objective of using PSC-derived cardiac cells is to structurally replace host cardiomyocytes which have been irreversibly damaged. This forms the basis of the "remuscularization" concept which entails the transplantation of cardiomyocytes, as mature as they can, or cardiac progenitors expected to complete their differentiation under the influence of local cues. The goal is that these cells stably engraft and 
seamlessly couple with host cardiomyocytes enabling the cellular graft to synchronously contribute to heart pump function while avoiding electrical instability. Several studies in both rodents and large animals, including non-human primates, have documented histologically the feasibility of generating large grafts recolonizing part of the scar tissue and predominantly made of cardiomyocytes, with evidence for their progressive maturation over time, an electrical coupling with host cardiomyocytes, as assessed by fluorescent calcium indicators (despite an often low connexin-43 immunoreactivity) and an associated improvement of left ventricular function of varying degree demonstrated by magnetic resonance imaging (Liu Y.-W. et al., 2018; Romagnuolo et al., 2019) or echocardiography and micro computerized tomography (Chong et al., 2014; Shiba et al., 2016). Despite being intellectually sound and attractive, this approach raises two major clinically relevant challenges: maintenance of long term cell survival and arrhythmias.

\section{Cell Survival}

If one targets the generation of a new myocardial tissue, it is expected that the grafted cells will remain engrafted and alive over time. Unfortunately, cells tend to die rapidly following transplantation, which has led to the investigation of multiple empowering strategies, primarily based on chemical or physical (heat shock) preconditioning and genetic engineering (Mohsin et al., 2011), but these approaches have been challenging to translate clinically, most likely because of their complexity, cost and difficulties to meet regulatory standards. In practice, three main factors of cell death have been identified. The first is the loss of cell anchorage to an extracellular matrix which occurs at the time of their usual dissociation before injection; this can be addressed by incorporation of the cells in a biomaterial which has a dual interest: (1) it provides a three-dimensional template conducive to extracellular matrix secretion enhancing cell cohesiveness, and (2) it acts as a shielding structure that increases cell retention. It is beyond the scope of this article to discuss the choice of biomaterials. Suffice is to say that if they are considered for catheter-based delivery, they should feature shear-thinning properties allowing their injection followed by an in situ gelation to improve retention of the matrix-encapsulated cells (Ban et al., 2014), whereas, they should have mechanical properties allowing to generate an easily manipulable patch if they are poised to an intraoperative epicardial application, as in the ESCORT trial and others. A second factor of cell death is the hostile nature of the environment they are implanted in, with a mix of inflammatory, hypovascularized and scarred areas which makes challenging for the transplanted cells to survive. One way of addressing this issue is to co-transplant them with supportive vascular and/or stromal cells to provide trophic and structural support. The critical role of non-cardiac cells (at a roughly 30\% ratio) for increasing the therapeutic potential of iPSC-derived cardiomyocytes has been established (Iseoka et al., 2018) and further confirmed recently by the ability of ESC-derived epicardial cells co-transplanted with ESC-derived cardiomyocytes to enhance cardiac graft size and heart function in athymic rats treated 4 days after a 60 min coronary artery ligation (Bargehr et al., 2019). The study by Gao et al. (2018) is of even greater clinical relevance in that it used a large animal (porcine) model to establish the functional benefits of a composite patch construct made of iPSCderived cardiomyocytes, endothelial and smooth muscle cells. In the clinics, these co-transplantation are technically doable as exemplified by the TAC-HF-II and the Japanese iPS sheet trials but they may complicate the cell manufacturing process. A third, and possible, the most challenging cause of cell death, is rejection of these allogeneic PSC derivatives. Currently, only drug-based immunosuppression is used to prevent rejection but despite the persisting uncertainties regarding the optimal drug regimen, it is admitted that these drugs are fraught with sideeffects which may lead to their discontinuation with an attendant loss of the grafted cells (Guan et al., 2020). A variant of this approach could be a "biological" immunomodulation by cotransplantation of MSC which have been shown, at least in a subcutaneous implantation model, to control allogeneic iPSC$\mathrm{CM}$ rejection via regulatory $\mathrm{T}$ cells and cell-cell contact with activated lymphocytes (Yoshida et al., 2020), however, because MSC are immune evasive and not immune privileged, they can only extend the survival of the co-transplanted iPSC-derived cardiomyocytes without preventing their ultimate disappearance (Yoshida et al., 2020).

\section{Arrhythmias}

A major concern raised by non-human primate studies in which ESC-derived cardiomyocytes have been transplanted has been the occurrence of ventricular arrhythmias (Chong et al., 2014; Shiba et al., 2016; Liu Y.-W. et al., 2018; Romagnuolo et al., 2019), some of which were life-threatening. Different mechanisms have been hypothesized but rather then re-entry induced by tracks of slow conduction, it seems that focal activation at the graft/host interface is a key trigger of these events (Liu Y.-W. et al., 2018; Romagnuolo et al., 2019). Of note, arrhythmias have usually been observed early, i.e., during the first post-transplantation weeks with a progressive diminution onward which could reflect a progressive in situ maturation of the graft toward a ventricular-like pattern. This supports the transplantation of a homogeneous population of cells featuring a mature electrophysiological phenotype but also emphasizes the importance of ensuring that the graft is appropriately purged from all cells which could still feature a pace-maker phenotype.

In an attempt to circumvent these issues while still targeting remuscularization of the diseased heart, other strategies have been developed which overall try either to reset the clock by restoring the ability of endogenous cardiomyocytes to divide or to convert host fibroblasts into new cardiomyocytes (reviewed in Sadek and Olson, 2020). The discussion of these strategies is beyond the scope of this paper but the important point is that a cell-induced improvement of function, which is the ultimate main objective, is not automatically correlated with an increase of the contractile cell pool. This has been well demonstrated in a mouse model of myocardial infarction where transplanted cardiovascular progenitor cells expressing a doxycycline-inducible MYC construct were shown to proliferate in the myocardium and then, following doxycycline removal, to differentiate in cardiomyocytes, endothelial and smooth muscle cells, leading to the formation of large grafts from the 
transplanted cells but without improvement of the contractile function (even though fibrosis was reduced) (Schwach et al., 2020). These data are in line with those published more than 10 years ago by van Laake et al. (2009) who had shown, in a mouse model, that post-infarction cardiac function was not improved by increasing graft size but rather seemed to be largely contributed by augmentation of the vascular density. Put together, these results are thus suggestive that other mechanisms than generation of new cardiomyocytes are involved in cell-induced improvement of outcomes, thereby lending support to the paracrine hypothesis.

\section{The Paracrine Hypothesis}

Aside from "remuscularization," a second mechanism whereby PSC-derived cardiac cells could act is paracrine signaling, i.e., the release of factors harnessing endogenous repair pathways (Garbern and Lee, 2013).

\section{Evidence for a Paracrine Mechanism of Action}

This hypothesis is strongly supported by three lines of reasoning. First, there is a consistent temporal discrepancy between the physical presence of cells in the transplanted tissue and the functional outcomes, i.e., an improvement in heart function is commonly demonstrated at a time where all grafted cells have disappeared. This applies to PSC cardiac derivatives as well. Thus, Riegler et al. (2015) found no difference in cardiac function between chronically infarcted rats transplanted with human ESC-derived cardiomyocytes mixed with collagen and those in which cells had previously been made non-viable by irradiation, thereby suggesting that cell engraftment was not directly responsible for functional improvements. Likewise, differences in ESC graft size have been shown not to translate into differences in the preservation of post-infarction heart function which further supports the idea that remuscularization may not be the key driver of the cell-associated therapeutic benefit (van Laake et al., 2009; Luo et al., 2014). More recently, ESCderived cardiovascular progenitor cells were reported to improve function of infarcted and adequately immunosuppressed nonhuman primates at a time where cells are no longer detectable (Zhu et al., 2018). Admittedly, another macaque study has reported the persistence of substantial grafts until 3 months after transplantation, possibly because of the use of more differentiated cardiomyocytes, but the scarcity of their connexin-43 expression still makes uncertain a functionally effective coupling with host cardiomyocytes (Liu Y.-W. et al., 2018) and this concern is strengthened by the finding of scar tissue isolating ESCand iPSC-cardiomyocyte grafts from the host myocardium of infarcted rats, which makes unlikely their direct contribution to cardiac contractility (van Laake et al., 2009; Lee et al., 2017). Second, cells are known to release a myriad of cytokines, growth factors and other biologics, many of them being packaged in extracellular vesicles (exosomes and microparticles) which can modulate the function of recipient cells through the delivery of their cargo (Patil et al., 2019) and this mechanism also pertains to vesicles released by PSC (Yuan et al., 2009). Extracellular vesicles can then shift recipient cell signaling pathways toward cardiac repair through multiple mechanisms, primarily mitigation of apoptosis, inflammation and fibrosis and stimulation of angiogenesis (Garikipati et al., 2018; Zhao et al., 2019), while the re-induction of a mitotic cycle of native cardiomyocytes leading to an increased contractile cell pool remains more controversial. Third, the extracellular vesicle-enriched secretome of stem cellderived cardiac cells (or of MSC) recapitulates (and even sometimes outweighs) the beneficial effects of their parental cells an observation which has now been made across a wide variety of preclinical cardiac (Kervadec et al., 2016; Adamiak et al., 2018; El Harane et al., 2018; Rogers et al., 2019) and non-cardiac disease models (reviewed in Desgres and Menasché, 2019) and is consistent with the finding of an overlap of the microRNA profiles between iPSC-cardiomyocytes (Santoso et al., 2020) or MSC (Shao et al., 2017) and their respective exosomes.

Relying on a paracrine mechanism of action implies that cells behave as platforms releasing bioactive molecules and will remain only transiently in the grafted tissue; however, as nobody still knows exactly how long is enough for the cells to release the factors underpinning their therapeutic benefits, the use of adjunctive biomaterials to extend their residency time can still be justified (Chen et al., 2018; Waters et al., 2018; Han et al., 2019). Importantly, rejection does not need to be prevented any longer; it should only be delayed, which implies a short-duration of immunosuppression and consequently reduces the risk of drug-induced side effects. We previously mentioned that in the ESCORT trial, immunosuppressive drugs were only given for 1 month with good tolerance and the Japanese trial entailing the use of iPSC-derived cardiomyocyte cell sheets has likewise planned a limited period (3 months) of immunosuppression.

\section{Use of the PSC Secretome Advantages}

The assumption that most, if not all, of the cardioprotective effects of stem cells can be duplicated by the exclusive use of their secretome has logically led to consider the latter as the only therapeutics that could be delivered. This approach has distinct clinically relevant advantages, including (1) a standardized pharma-like manufacturing process, (2) a likely lack of immunogenicity, provided the cells of origin themselves express little, if any, of the HLA I and II, which is the case for iPSC-derived cardiovascular progenitors (Lima Correa et al., 2020), and (3) a functional stability under cryo-storage compatible with an off-the-shelf availability. However, these presumed benefits have to be compounded by the still limited number of large animal proof-of-concept studies (Timmers et al., 2011; Gallet et al., 2017) and the absence, so far, of clinical trials allowing a thorough assessment of this approach in the context of heart failure.

\section{Challenges}

Regardless of the cautionary words above, the translational use of the secretome requires to address at least four main challenges, the first of which is the choice of the parental cells. Although the RNA and protein cargo of undifferentiated ESC (Khan et al., 2015) and iPSC (Bobis-Wozowicz et al., 2015) has shown cardio-protective effects both in vitro and in animal models of myocardial infarction, the clinical use of such a secretome would likely raise safety issues because of its possible enrichment 
with pluripotency markers (Ratajczak et al., 2006), which rather leads to privilege more differentiated cells as the source material. In this context, and in parallel to what has been shown for cells, the bioactivity of the secretome of cardiac-committed cells outweighs that of non-cardiac cells (Barile et al., 2018), possibly because the released factors are better tailored to the specific biology of the target cardiac tissue; even within the cardiac cell population, the secretome released by early progenitor cells seems to feature superior cardioprotective properties (Agarwal et al., 2017; Könemann et al., 2019) and these data are in line with our observations (El Harane et al., 2018) and those of others (Malik et al., 2013) that untreated adult cardiomyocytes secrete minimal amounts of exosomes. These findings strongly rationalize the choice of PSC as the parental cells because of the dual possibility of differentiating them into cardiaccommitted cells and stopping the differentiation process at an early developmental stage. For this reason, our next clinical trial will entail the administration of an extracellular vesicleenriched secretome of iPSC-derived cardiovascular progenitor cells (El Harane et al., 2018). A second challenge is the mode of delivery of the secretome. If direct intramyocardial injections are considered, a one-shot delivery without any additional carrier exposes to a rapid wash-out and an attendant loss of efficacy. Thus, the incorporation of the cell-produced biologics into biomaterials enabling a sustained release (Chen et al., 2018; Waters et al., 2018), much like for traditional stem cell therapy, can be an effective means of extending their retention and improving outcomes and this concept applies to PSC-derived cardiac cells (Liu B. et al., 2018). Here, a distinct advantage of cellderived biologics is that they can be successfully embedded into scaffolds suitable for long-term cryopreservation and immediate availability, thereby overcoming survival and storage issues associated with the use of cells (Huang et al., 2020). However, a more appealing means of leveraging the acellular nature of the secretome is to deliver it intravenously. Although a limited amount of the injectate may then reach the target organ, the intravenous route is yet associated with a functional benefit which has been demonstrated across a wide variety of preclinical models of acute myocardial infarction (Timmers et al., 2011; Ciullo et al., 2019), Duchenne (Rogers et al., 2019) and chemotherapyinduced (Singla et al., 2012; Vandergriff et al., 2015; Sun et al., 2018; Milano et al., 2019) cardiomyopathies, as well as in noncardiac disease models. One postulated mechanism of action of these intravenously injected EV-enriched secretomes is that following their predominant uptake by macrophages (Morishita et al., 2017) and liver sequestration (Wiklander et al., 2015), they could act like cells through a systemic modulation of inflammation triggering tissue-protective signals which are then conveyed to the target organ by the circulating cells (Walker et al., 2012). It is clear that the intravenous route has clinically relevant advantages: it is simple as it does not require costly equipment and facilities; more importantly, it is non-invasive and as such allows repeated administrations, which could be critical for optimizing the therapeutic benefit, as suggested by the finding that repeated administrations of transplanted cells are superior to the single administration of an equivalent cumulative dose (Tang et al., 2018). Of note, while all modes of cells/cell products delivery target the same objective, i.e., an improvement in heart function along with a reversal of adverse ventricular remodeling, they might conceivably reach this goal through different mechanisms of action, i.e., the predominant replenishment of the contractile cell pool along with an increased angiogenesis in the case of direct intramyocardial cardiac cell implantation as opposed to a systemic regulation of inflammation following intravenous infusions.

The last two translational challenges raised by the use of the cellular secretome are its degree and method of purification as well as the characterization of its content. However, these issues are not specific for PSC used as the parental cells and their discussion is beyond the scope of this chapter (for reviews, see Andriolo et al., 2018; Théry et al., 2018).

\section{A Common Mechanism-Independent Issue: Safety}

Regardless of the putative mechanism of action, safety is obviously a key issue because the presence in the cell product of still undifferentiated and/or transformed cells could lead to their uncontrolled proliferation and give rise to a teratoma or a teratocarcinoma. The opponents of ESC have obviously rushed on this risk to demonize ESC (Wysoczynski and Bolli, 2020) in contempt of the actual data which show that although the first five patients to receive ESC derivatives, in this case oligodendrocytes for spinal cord injury, are now at 8 years of their treatment without any warning signal (Press release from Asterias Biotherapeutics Inc., January 24, 2019). Likewise, the first patient of the ESCORT trial has now a more than 5 year-follow up and is doing well without any abnormality on imaging studies (computerized tomography and ${ }^{18}$ F-FDG positron emission tomography scans). Nevertheless, it is obviously critical to purify the differentiated cells to ensure that they are no longer contaminated with unwanted and still pluripotent cells.

Multiple purification methods have been developed (reviewed in Ban et al., 2017; Moon et al., 2017), of which only a sorting based on surface markers is currently suitable for largescale GMP-compliant applications. In the ESCORT trial, we used SSEA-1 as a marker for cells which were no longer undifferentiated and used magnetic bead-bound anti-SSEA1 antibodies for selecting them. Even though this mode of immunomagnetic positive selection has been used for years for enriching in hematopoietic cell populations, a negative mode of selection targeting markers for pluripotency (Tang et al., 2011) is more appealing in that it would allow the final cell therapy product for patient use to remain magnetic bead-free. Other strategies based on microfluidics or field-flow fractionation are currently investigated and might be of interest if they can be scaled-up under GMP conditions. Of note, selection of the cardiac-committed cells is primarily relevant to the use of cardiovascular progenitors where stage-specific markers have to be used (Isl-1 in the ESCORT trial) since an extended period of culture is expected to yield an almost pure population of cardiomyocytes whose identity can be confirmed by a battery of markers (Flk-1, PDGFR- $\alpha$, signal-regulatory protein alpha [(SIRPA)] and vascular cell adhesion molecule 1 (VCAM1)] 
and which, in principle, does not harbor undifferentiated cells any longer.

However, regardless of the cell culture strategy, it is mandatory to ensure that the final product which will be delivered to the patient has no tumorigenic potential. This first implies in vitro checking for its genetic stability to eliminate the occurrence of cancer-driving mutations that can be induced by culture conditions and time in culture (Goldring et al., 2011; Oliveira et al., 2014). Several quality control metrics have been proposed to ensure that oncogenic networks have not been activated (reviewed in Assou et al., 2018). As an example, the cardiovascular SSEA-1 ${ }^{+}$cells used in the ESCORT trial were assessed by karyotyping, fluorescence in situ hybridization (FISH) and array comparative genomic hybridization (aCGH). Of note, iPSC may be more prone to genetic/epigenetic alterations than ESC because of the potential of mutations already present in the parental cells from which they are reprogrammed (Ben-David and Benvenisty, 2011; Oliveira et al., 2014), with the caveat that it can be difficult to establish a correlation between genetic modifications of the cells and the actual risk that will form a tumor in vivo. Maybe, in the future, the organs-onchip technology will provide a human-like micro-environment more suitable for an accurate risk prediction. The identity of the cardiac-committed product also needs to be tested by lineage-specific markers, usually by flow cytometry and/or gene sequencing, in particular to ensure that pluripotency genes have been appropriately knocked down. It may also be advisable to enrich the risk analysis with assays evaluating the potential of the cells to cause genotoxicity and chromosomal damage.

Despite the utility of these in vitro tests, tumorigenicity studies in animals still represent a major pillar of the preclinical safety assessment. Several factors have then to be taken into consideration, which include the number of cells to be inoculated, the duration of follow-up, the site of transplantation and the limit of detection of the relevant assays (Sato et al., 2019). The choice of the animal model is particularly critical, keeping in mind that most studies entail transplanting human cells into rodents and, as such, should be interpreted cautiously since xenotransplantation is less likely to induce teratomas than allografts (Erdö et al., 2003). This has been the main argument for us to test Rhesus ESCderived cardiovascular progenitors in infarcted Rhesus monkeys with the premise that such an intraspecies transplantation would sensitize the potential occurrence of a tumor (Blin et al., 2010). Importantly, these teratoma experiments should include spiking experiments with different ratios of undifferentiated/lineagecommitted cells to identify the threshold above which a tumor occurs and thus helps defining lot release criteria (Priest et al., 2015). This information is a critical component of the risk assessment. Finally, off-target adverse effects have to be ruled out by biodistribution studies.

\section{PERSPECTIVES}

\section{Remuscularization}

For those who remain committed to use PSC-derived cardiaccommitted cells as physical and expectedly permanent substitutes for the lost cardiomyocytes, there are at least three areas of research which need to be prioritized. The first is to define the optimal stage of differentiation at which cells should be transplanted. As mentioned above, there are no robust arguments favoring early progenitors versus more mature cardiomyocytes but, assuming that the latter could more efficiently increase pump function, it is mandatory to address the risk of arrhythmias by optimizing the maturation state of the transplanted cardiomyocytes and thus mitigate an electrical mismatch at the graft/host interface (Romagnuolo et al., 2019); this can be achieved by a variety of strategies including co-culture with endothelial cells, prolongation of the culture time, control of the composition, topography and stiffness of the extracellular matrix, mechanical and electrical stimulation (Le and Hasegawa, 2019). The second area of research pertains to the development of strategies allowing an immune tolerance of these allogeneic cells in order to avoid the use of high doses of immunosuppressive drugs and their cohort of adverse effects. In this setting, the use of HLA-haplotyped cell lines (Neofytou et al., 2015) could be helpful by allowing a better match between the grafted cells and the immune profile of the recipient and is clinically doable as HLA-matched cells are currently transplanted in a Parkinson trial: https://upload.umin.ac.jp/cgi-open-bin/ctr_e/ctr_view.cgi? recptno $=$ R000038278. However, the most conceptually attractive option could be the use of gene editing to generate cell lines no longer expressing HLA-I and -II antigens but engineered to express molecules preventing cell destruction by Natural Killer cells (Xu H. et al., 2019), provided that the efficacy and safety of these "universal" cell lines can be validated. One step further, co-transplanting cardiomyocytes and dendritic cells derived from the same PSC line might induce a selective tolerance to $\mathrm{T}$ cells reactive to the alloantigens expressed by the PSC derivatives. In the context of these efforts to "lighten" immunosuppressive regimens, another approach, possibly easier to implement in the clinics, could be the use of regulatory $\mathrm{T}$ cells or even their derived exosomes which have been shown to successfully extend liver graft survival (Chen et al., 2019).

Finally, even though the success of pro-survival approaches could enable a prolonged engraftment of the cells, it is likely that their number will progressively decrease over time. This assumption is supported by the finding that cardiac function was significantly improved in mice injected with ESC-derived cardiomyocytes at 4 weeks after transplantation but that this benefit was not retained at 3 months (van Laake et al., 2007), thereby suggesting that maintenance of a therapeutic effect likely requires repeated administrations. In the clinics, this can only be achieved, easily and safely, by intravenous injections. Admittedly, however, intravenously injected ESC-derived endothelial cells or iPSC-derived neural stem cells have been therapeutically effective in ischemic hindlimb (Huang et al., 2010) and amyotrophic lateral sclerosis (Nizzardo et al., 2014) models, respectively, without causing short-term adverse events, but one could be concerned about the safety of a systemic delivery of PSC derivatives and it is uncertain that such a strategy would be approved by the regulators (it might be the reason why the Chinese trial mentioned above and which had planned intravenous infusions of iPSC-derived cardiomyocytes in 3 heart 
failure patients has not yet started 18 months after its official registration). In this context, an innovative approach has been proposed which consists of implanting an epicardial device connected to a subcutaneous port which can be periodically replenished with. The extent to which this system, which has shown promising results in a rodent model of myocardial infarction (Whyte et al., 2018), can be translated clinically remains to be established.

\section{Paracrine Signaling}

Reliance on a paracrine mechanism of action logically leads to consider to exclusively deliver the cellular secretome even though its effects on in vitro potency assays may not be representative of what happens when it is directly released by the parental cells in vivo. This limitation, however, may not be so relevant as demonstrated almost 10 years ago by Timmers et al. (2011) who showed, in a pig model of myocardial infarction, the protective effects of the intravenously infused conditioned medium (only clarified and concentrated) of ESC-derived MSC. Further confirmation has been brought more recently in a rat model of myocardial infarction in which a single intramyocardial injection of the total conditioned media released by neonatal human CSC was significantly more effective functionally than either the parental cells of their purified exosomal fraction (Sharma et al., 2017). Nevertheless, one area of research is to identify the key drivers of the biological effects of the cellular secretome and many different miRNAs and proteins have been reported as the most effective candidates. While it is tempting to identify a short list of compounds in the perspective of synthetizing them as a multi-targeted drug, it could indeed be counter-productive to deconstruct the cargo of the secretome because of the multiplicity of its components and their possible interactions leading to synergistic effects, notwithstanding the challenge of artificially recapitulating a complex repertoire of bioactive molecules. Another reason for keeping the whole extracellular vesicle payload intact is that it can be shuttled in the recipient cells without the risk of degradation because of the protection afforded by the lipid bilayer of the vesicles whereas it is unlikely it would still be the case if its individual components had to be delivered individually. A second area of research pertains to the means of "priming" the parental cells during the culture period to enrich the extracellular vesicle package with proteins and other biologics that can bolster their biological effects (Wiklander et al., 2019; Xu R. et al., 2019; Yuan et al., 2019). A third clinically relevant perspective pertains to the optimized delivery of the cellular secretome. Although using source cells which share the same repertoire of surface receptors as those of the target tissue can yet be therapeutically beneficial, as discussed above, a greater benefit could likely be yielded by a more selective targeting of the injectate toward the heart, which can be achieved by two different approaches. The first consists of engineering the parental cells to make them overexpressing receptors expected to traffic to their extracellular vesicles and whose display on the external part of the vesicular membrane can enhance recognition by target cells, docking and vesicle uptake. This strategy has been shown successful for promoting homing of intravenously injected exosomes derived from cardiac progenitor cells overexpressing CXCR4 to enhance interaction of this receptor with its SDF- $1 \alpha$ ligand which is upregulated in ischemic tissues (Ciullo et al., 2019). This approach, however, is challenged by the risk of peptide degradation (Hung and Leonard, 2015), hence the interest of an alternate approach based on the direct engineering of the secreted vesicles by anchorage of cardiac-specific peptides to their membrane (Vandergriff et al., 2018) or modifications of their glysosylation pattern to promote binding to endothelial selectins (Sackstein, 2009; Lo et al., 2016). A last clinically relevant issue is dosing. There is consistent evidence that the effects of extracellular vesicles are dose-dependent (Kervadec et al., 2016) while the apparently low number of miRNA carried by exosomes (Chevillet et al., 2014) likely requires large amounts of them to be transferred to convey a significant biological effect, particularly following a systemic delivery. Different metrics can be considered here such as an absolute number of particles, a protein concentration, the vesicle number to protein ratio or a "cell equivalent," i.e., the amount of particles assumed to be released by a given number of the parental cells but no consensus has emerged yet.

In conclusion, while iPSC look more attractive for disease modeling and drug screening, both ESC and iPSC share the same potential for inducing heart repair and possibly regeneration. For reasons related to practicality, iPSC-derived cardiac-committed cells, regardless of their stage of differentiation, may provide a better cost-effective model, particularly if they are primarily used as ex vivo biofactories producing a biologically active secretome which would then represent the therapeutics delivered to the patient. This approach would allow to leverage the cardioprotective potential of PSC derivatives while overcoming the safety issues that might be associated with their direct delivery. Future clinical studies will tell whether such an expectation can be really met. In the meantime, the observation that by the end of 2019, there were at least 54 registered trials testing PSC derivatives (Kobold et al., 2020) provides compelling evidence that regardless of the cell source (ESC or iPSC), the clinical indication and the delivery strategy, PSC-derived lineage-specific cells have now integrated the armamentarium of therapies against a wide variety of diseases.

\section{AUTHOR CONTRIBUTIONS}

PM wrote the manuscript.

\section{ACKNOWLEDGMENTS}

I thank the French Ministry of Health (Programme Hospitalier de Recherche Clinique PCR11001, P100303) and Assistance Publique-Hôpitaux de Paris, l'Institut National de la Recherche Médicale (Inserm), the LabEx REVIVE (ANR-10-LABX-73), the French Association Against Myopathies (EVEDOX, Application \#22378), the Fondation de France (FDF/2014 00047970), the Fondation pour la Recherche Médicale (PME20180639496), and the Fondation de l'Avenir (AP-RM-18-017) for their funding support. 


\section{REFERENCES}

Adamiak, M., Cheng, G., Bobis-Wozowicz, S., Zhao, L., Kedracka-Krok, S., Samanta, A., et al. (2018). Induced pluripotent stem cell (iPSC)-Derived extracellular vesicles are safer and more effective for cardiac repair than iPSCs. Circ. Res. 122, 296-309. doi: 10.1161/CIRCRESAHA.117.311769

Agarwal, U., George, A., Bhutani, S., Ghosh-Choudhary, S., Maxwell, J. T., Brown, M. E., et al. (2017). Experimental, systems, and computational approaches to understanding the microrna-mediated reparative po-tential of cardiac progenitor cell-derived exosomes from pediatric pa-tientsnovelty and significance. Circ. Res. 120, 701-712. doi: 10.1161/CIRCRESAHA.116.309935

Andriolo, G., Provasi, E., Lo Cicero, V., Brambilla, A., Soncin, S., Torre, T., et al. (2018). Exosomes from human cardiac progenitor cells for therapeutic applications: development of a GMP-Grade manufacturing method. Front. Physiol. 9:1169. doi: 10.3389/fphys.2018.01169

Assou, S., Bouckenheimer, J., and De Vos, J. (2018). Concise review: assessing the genome integrity of human induced pluripotent stem cells: what quality control metrics? Stem Cells 36, 814-821. doi: 10.1002/stem.2797

Ban, K., Bae, S., and Yoon, Y.-S. (2017). Current strategies and challenges for purification of cardiomyocytes derived from human pluripotent stem cells. Theranostics 7, 2067-2077. doi: 10.7150/thno.19427

Ban, K., Park, H.-J., Kim, S., Andukuri, A., Cho, K.-W., Hwang, J. W., et al. (2014). Cell therapy with embryonic stem cell-derived cardiomyocytes encapsulated in injectable nanomatrix gel enhances cell engraftment and promotes cardiac repair. ACS Nano 8, 10815-10825. doi: 10.1021/nn504617g

Bargehr, J., Ong, L. P., Colzani, M., Davaapil, H., Hofsteen, P., Bhandari, S., et al. (2019). Epicardial cells derived from human embryonic stem cells augment cardiomyocyte-driven heart regeneration. Nat. Biotechnol. 37, 895-906. doi: 10.1038/s41587-019-0197-9

Barile, L., Cervio, E., Lionetti, V., Milano, G., Ciullo, A., Biemmi, V., et al. (2018). Cardioprotection by cardiac progenitor cell-secreted exosomes: role of pregnancy-associated plasma protein-A. Cardiovasc. Res. 114, 992-1005. doi: 10.1093/cvr/cry055

Bellamy, V., Vanneaux, V., Bel, A., Nemetalla, H., Emmanuelle Boitard, S., Farouz, Y., et al. (2015). Long-term functional benefits of human embryon-ic stem cell-derived cardiac progenitors embedded into a fibrin scaffold. J. Heart Lung Transplant. 34, 1198-1207. doi: 10.1016/j.healun.2014.10.008

Ben-David, U., and Benvenisty, N. (2011). The tumorigenicity of human embryonic and induced pluripotent stem cells. Nat. Rev. Cancer 11, 268-277. doi: $10.1038 / \mathrm{nrc} 3034$

Blin, G., Nury, D., Stefanovic, S., Neri, T., Guillevic, O., Brinon, B., et al. (2010). A purified population of multipotent cardiovascular progenitors derived from primate pluripotent stem cells engrafts in postmyocardial infarcted nonhuman primates. J. Clin. Invest. 120, 1125-1139. doi: 10.1172/JCI40120

Bobis-Wozowicz, S., Kmiotek, K., Sekula, M., Kedracka-Krok, S., Kamycka, E., Adamiak, M., et al. (2015). Human induced pluripotent stem cell-derived microvesicles transmit RNAs and proteins to recipient mature heart cells modulating cell fate and behavior: hiPSC-MVs Transmit RNAs and proteins to heart cells. Stem Cells 33, 2748-2761. doi: 10.1002/stem.2078

Caspi, O., Huber, I., Kehat, I., Habib, M., Arbel, G., Gepstein, A., et al. (2007). Transplantation of human embryonic stem cell-derived cardiomyocytes improves myocardial performance in infarcted rat hearts. J. Am. Coll. Cardiol. 50, 1884-1893. doi: 10.1016/j.jacc.2007.07.054

Chen, C. W., Wang, L. L., Zaman, S., Gordon, J., Arisi, M. F., Venkataraman, C. M., et al. (2018). Sustained release of endothelial progenitor cell-derived extracellular vesicles from shear-thinning hydrogels improves angiogene-sis and promotes function after myocardial infarction. Cardiovasc. Res. 114, 10291040. doi: $10.1093 / \mathrm{cvr} / \mathrm{cvy} 067$

Chen, L., Huang, H., Zhang, W., Ding, F., Fan, Z., and Zeng, Z. (2019). exosomes derived from $\mathrm{T}$ regulatory cells suppress $\mathrm{CD} 8+$ Cytotoxic $\mathrm{T}$ Lympho-cyte proliferation and prolong liver allograft survival. Med. Sci. Monit. 25, 48774884. doi: 10.12659/MSM.917058

Chevillet, J. R., Kang, Q., Ruf, I. K., Briggs, H. A., Vojtech, L. N., Hughes, S. M., et al. (2014). Quantitative and stoichiometric analysis of the microRNA content of exosomes. Proc. Natl. Acad. Sci. U.S.A. 111, 14888-14893. doi: 10.1073/pnas. 1408301111

Chong, J. J. H., Yang, X., Don, C. W., Minami, E., Liu, Y.-W., Weyers, J. J., et al. (2014). Human embryonic-stem-cell-derived cardiomyocytes regenerate non-human primate hearts. Nature 510, 273-277. doi: 10.1038/nature 13233

Citro, L., Naidu, S., Hassan, F., Kuppusamy, M. L., Kuppusamy, P., Angelos, M. G., et al. (2014). Comparison of human induced pluripotent stem-cell derived cardiomyocytes with human mesenchymal stem cells following acute myocardial infarction. PLoS One 9:e116281. doi: 10.1371/journal.pone.011 6281

Ciullo, A., Biemmi, V., Milano, G., Bolis, S., Cervio, E., Fertig, E. T., et al. (2019). Exosomal expression of CXCR4 targets cardioprotective vesicles to myocardial infarction and improves outcome after systemic Ad-ministration. Int. J. Mol. Sci. 20:468. doi: 10.3390/ijms20030468

Desgres, M., and Menasché, P. (2019). Clinical translation of pluripotent stem cell therapies: challenges and considerations. Cell Stem Cell 25, 594-606. doi: 10.1016/j.stem.2019.10.001

El Harane, N., Kervadec, A., Bellamy, V., Pidial, L., Neametalla, H. J., Perier, M.-C., et al. (2018). Acellular therapeutic approach for heart failure: in vitro production of extracellular vesicles from human cardiovascular progeni-tors. Eur. Heart J. 39, 1835-1847. doi: 10.1093/eurheartj/ehy012

Erdö, F., Bührle, C., Blunk, J., Hoehn, M., Xia, Y., Fleischmann, B., et al. (2003). Host-dependent tumorigenesis of embryonic stem cell transplantation in experimental stroke. J. Cereb. Blood Flow Metab. 23, 780-785. doi: 10.1097/ 01.WCB.0000071886.63724.FB

Fernandes, S., Chong, J. J. H., Paige, S. L., Iwata, M., Torok-Storb, B., Keller, G., et al. (2015). Comparison of human embryonic stem cell-derived car-diomyocytes, cardiovascular progenitors, and bone marrow mononu-clear cells for cardiac repair. Stem Cell Rep. 5, 753-762. doi: 10.1016/j.stemcr.2015.09.011

Florea, V., Rieger, A. C., DiFede, D. L., El-Khorazaty, J., Natsumeda, M., Banerjee, M. N., et al. (2017). Dose comparison study of allogeneic mesenchymal stem cells in patients with ischemic cardiomyopathy (The TRIDENT Study). Circ. Res. 121, 1279-1290. doi: 10.1161/CIRCRESAHA.117.311827

Gallet, R., Dawkins, J., Valle, J., Simsolo, E., de Couto, G., Middleton, R., et al. (2017). Exosomes secreted by cardiosphere-derived cells reduce scarring, attenuate adverse remodelling, and improve function in acute and chronic porcine myocardial infarction. Eur. Heart J. 38, 201-211. doi: 10.1093/ eurheartj/ehw240

Gao, L., Gregorich, Z. R., Zhu, W., Mattapally, S., Oduk, Y., Lou, X., et al. (2018). Large cardiac muscle patches engineered from human induced-pluripotent stem cell-derived cardiac cells improve recovery from myocardial infarction in swine. Circulation 137, 1712-1730. doi: 10.1161/CIRCULATIONAHA.117. 030785

Garbern, J. C., and Lee, R. T. (2013). Cardiac stem cell therapy and the promise of heart regeneration. Cell Stem Cell 12, 689-698. doi: 10.1016/j.stem.2013.05.008

Garikipati, V. N. S., Shoja-Taheri, F., Davis, M. E., and Kishore, R. (2018). Ex-tracellular vesicles and the application of system biology and computational modeling in cardiac repair. Circ. Res. 123, 188-204. doi: 10.1161/CIRCRESAHA.117.311215

Goldring, C. E. P., Duffy, P. A., Benvenisty, N., Andrews, P. W., Ben-David, U., Eakins, R., et al. (2011). Assessing the safety of stem cell therapeutics. Cell Stem Cell 8, 618-628. doi: 10.1016/j.stem.2011.05.012

Guan, X., Xu, W., Zhang, H., Wang, Q., Yu, J., Zhang, R., et al. (2020). Transplantation of human induced pluripotent stem cell-derived cardiomyo-cytes improves myocardial function and reverses ventricular remodeling in infarcted rat hearts. Stem Cell Res. Ther. 11:73. doi: 10.1186/s13287-020-01602-0

Guo, R., Morimatsu, M., Feng, T., Lan, F., Chang, D., Wan, F., et al. (2020). Stem cell-derived cell sheet transplantation for heart tissue repair in myocardial infarction. Stem Cell Res. Ther. 11:19. doi: 10.1186/s13287-019-1536-y

Halbach, M., Baumgartner, S., Sahito, R. G. A., Krausgrill, B., Maass, M., Peinkofer, G., et al. (2014). Cell persistence and electrical integration of transplanted fetal cardiomyocytes from different developmental stages. Int. J. Cardiol. 171, e122-e124. doi: 10.1016/j.ijcard.2013.12.115

Han, C., Zhou, J., Liang, C., Liu, B., Pan, X., Zhang, Y., et al. (2019). Human umbilical cord mesenchymal stem cell derived exosomes encapsulated in functional peptide hydrogels promote cardiac repair. Biomater. Sci. 7, 29202933. doi: $10.1039 / \mathrm{C} 9 \mathrm{BM} 00101 \mathrm{H}$

Huang, K., Ozpinar, E. W., Su, T., Tang, J., Shen, D., Qiao, L., et al. (2020). An off-the-shelf artificial cardiac patch improves cardiac repair after myocardial infarction in rats and pigs. Sci. Transl. Med. 12:eaat9683. doi: 10.1126/ scitranslmed.aat 9683 
Huang, N. F., Niiyama, H., Peter, C., De, A., Natkunam, Y., Fleissner, F., et al. (2010). Embryonic stem cell-derived endothelial cells engraft into the is-chemic hindlimb and restore perfusion. Arterioscler. Thromb. Vasc. Biol. 30, 984-991. doi: 10.1161/ATVBAHA.110.202796

Hung, M. E., and Leonard, J. N. (2015). Stabilization of Exosome-targeting Peptides via Engineered Glycosylation. J. Biol. Chem. 290, 8166-8172. doi: 10.1074/ jbc.M114.621383

Ichimura, H., Kadota, S., Kashihara, T., Yamada, M., Ito, K., Kobayashi, H., et al. (2020). Increased predominance of the matured ventricular subtype in embryonic stem cell-derived cardiomyocytes in vivo. Sci. Rep. 10:5268. doi: 10.1038/s41598-020-68373-9

Iseoka, H., Miyagawa, S., Fukushima, S., Saito, A., Masuda, S., Yajima, S., et al. (2018). Pivotal role of non-cardiomyocytes in electromechanical and therapeutic potential of induced pluripotent stem cell-derived engi-neered cardiac tissue. Tissue Eng Part A 24, 287-300. doi: 10.1089/ten.TEA.2016. 0535

Ishida, M., Miyagawa, S., Saito, A., Fukushima, S., Harada, A., Ito, E., et al. (2019). Transplantation of human-induced pluripotent stem cell-derived cardiomyocytes is superior to somatic stem cell therapy for restoring cardiac function and oxygen consumption in a porcine model of myocardial infarction. Transplantation 103, 291-298. doi: 10.1097/TP.0000000000002384

Kabat, M., Bobkov, I., Kumar, S., and Grumet, M. (2020). Trends in mesenchy-mal stem cell clinical trials 2004-2018: Is efficacy optimal in a narrow dose range? Stem Cells Transl. Med. 9, 17-27. doi: 10.1002/sctm.19-0202

Kervadec, A., Bellamy, V., El Harane, N., Arakélian, L., Vanneaux, V., Cacciapuoti, I., et al. (2016). Cardiovascular progenitor-derived extracellular vesicles recapitulate the beneficial effects of their parent cells in the treatment of chronic heart failure. J. Heart Lung Trans Plantation 35, 795-807. doi: 10.1016/j.healun. 2016.01 .013

Khan, M., Nickoloff, E., Abramova, T., Johnson, J., Verma, S. K., Krishnamurthy, P., et al. (2015). Embryonic stem cell-derived exosomes promote en-dogenous repair mechanisms and enhance cardiac function following myocardial infarction. Circ. Res. 117, 52-64. doi: 10.1161/CIRCRESAHA.117.305990

Kobold, S., Guhr, A., Mah, N., Bultjer, N., Seltmann, S., Seiler Wulczyn, A. E. M., et al. (2020). A manually curated database on clinical studies in-volving cell products derived from human pluripotent stem cells. Stem Cell Rep. 15, 546555. doi: 10.1016/j.stemcr.2020.06.014

Könemann, S., Sartori, L. V., Gross, S., Hadlich, S., Kühn, J.-P., Samal, R., et al. (2019). Cardioprotective effect of the secretome of Sca-1+ and Sca-1- cells in heart failure: not equal, but equally important? Cardiovas. Res.. 116, 566-575. doi: $10.1093 / \mathrm{cvr} / \mathrm{cvz} 140$

Le, M. N. T., and Hasegawa, K. (2019). Expansion culture of human pluripotent stem cells and production of cardiomyocytes. Bioengineering 6:48. doi: 10.3390/ bioengineering6020048

Lee, W. H., Chen, W.-Y., Shao, N.-Y., Xiao, D., Qin, X., Baker, N., et al. (2017). Comparison of non-coding RNAs in exosomes and functional efficacy of human embryonic stem cell- versus induced pluripotent stem cell-derived cardiomyocytes. Stem Cells 35, 2138-2149. doi: 10.1002/stem.2669

Li, T.-S., Cheng, K., Malliaras, K., Smith, R. R., Zhang, Y., Sun, B., et al. (2012). Direct comparison of different stem cell types and subpopulations reveals superior paracrine potency and myocardial repair efficacy with cardiospherederived cells. J. Am. Coll. Cardiol. 59, 942-953. doi: 10.1016/j.jacc.2011. 11.029

Liao, S., Zhang, Y., Ting, S., Zhen, Z., Luo, F., Zhu, Z., et al. (2019). Potent im-munomodulation and angiogenic effects of mesenchymal stem cells versus cardiomyocytes derived from pluripotent stem cells for treatment of heart failure. Stem Cell Res. Ther. 10:78. doi: 10.1186/s13287-019-1183-3

Lima Correa, B., El Harane, N., Gomez, I., Rachid Hocine, H., Vilar, J., Desgres, M., et al. (2020). Extracellular vesicles from human cardiovascular pro-genitors trigger a reparative immune response in infarcted hearts. Cardi Ovasc. Res. 12:cvaa028. doi: $10.1093 / \mathrm{cvr} / \mathrm{cvaa} 028$

Liu, B., Lee, B. W., Nakanishi, K., Villasante, A., Williamson, R., Metz, J., et al. (2018). Cardiac recovery via extended cell-free delivery of extracellular vesicles secreted by cardiomyocytes derived from induced pluripotent stem cells. Nat. Biomed. Eng. 2, 293-303. doi: 10.1038/s41551-0180229-7

Liu, Y.-W., Chen, B., Yang, X., Fugate, J. A., Kalucki, F. A., Futakuchi-Tsuchida, A., et al. (2018). Human embryonic stem cell-derived cardiomyocytes restore function in infarcted hearts of non-human primates. Nat. Biotechnol. 36, 597605. doi: $10.1038 /$ nbt. 4162

Lo, C. Y., Weil, B. R., Palka, B. A., Momeni, A., Canty, J. M., and Neelamegham, S. (2016). Cell surface glycoengineering improves selectin-mediated ad-hesion of mesenchymal stem cells (MSCs) and cardiosphere-derived cells (CDCs): pilot validation in porcine ischemia-reperfusion model. Bio Mater. 74, 19-30. doi: 10.1016/j.biomaterials.2015.09.026

Luo, J., Weaver, M. S., Dennis, J. E., Whalen, E., Laflamme, M. A., and Allen, M. D. (2014). Targeting survival pathways to create infarct-spanning bridges of human embryonic stem cell-derived cardiomyocytes. J. Thorac. Car Diovasc. Surg. 148, 3180.e1-3188.e1. doi: 10.1016/j.jtcvs.2014.06.087

Malik, Z. A., Kott, K. S., Poe, A. J., Kuo, T., Chen, L., Ferrara, K. W., et al. (2013). Cardiac myocyte exosomes: stability, HSP60, and proteomics. Am. J. Physiol. Heart Circ. Physiol. 304, H954-H965. doi: 10.1152/ajpheart.00835.2012

Menasché, P., Vanneaux, V., Fabreguettes, J.-R., Bel, A., Tosca, L., Garcia, S., et al. (2015). Towards a clinical use of human embryonic stem cell-derived cardiac progenitors: a translational experience. Eur. Heart J. 36, 743-750. doi: 10.1093/ eurheartj/ehu192

Menasché, P., Vanneaux, V., Hagège, A., Bel, A., Cholley, B., Parouchev, A., et al. (2018). Transplantation of human embryonic stem cell-derived cardiovascular progenitors for severe ischemic left ventricular dys-function. J. Am. Coll. Cardiol. 71, 429-438. doi: 10.1016/j.jacc.2017.11.047

Milano, G., Biemmi, V., Lazzarini, E., Balbi, C., Ciullo, A., Bolis, S., et al. (2019). Intravenous administration of cardiac progenitor cell-derived exosomes protects against doxorubicin/trastuzumab-induced cardiac toxicity. Cardiovasc. Res. 116, 383-392. doi: 10.1093/cvr/cvz108

Mohsin, S., Siddiqi, S., Collins, B., and Sussman, M. A. (2011). Empowering adult stem cells for myocardial regeneration. Circ. Res. 109, 1415-1428. doi: 10.1161/ CIRCRESAHA.111.243071

Moon, S.-H., Bae, D., Jung, T.-H., Chung, E.-B., Jeong, Y.-H., Park, S.-J., et al. (2017). From bench to market: preparing human pluripotent stem cells derived cardiomyocytes for various applications. Int. J. Stem Cells 10, 1-11. doi: 10. 15283/ijsc17024

Morishita, M., Takahashi, Y., Nishikawa, M., and Takakura, Y. (2017). Pharmacokinetics of exosomes-an important factor for elucidating the biologi-cal roles of exosomes and for the development of exosome-based therapeutics. J. Pharm. Sci. 106, 2265-2269. doi: 10.1016/j.xphs.2017.02.030

Neofytou, E., O’Brien, C. G., Couture, L. A., and Wu, J. C. (2015). Hurdles to clinical translation of human induced pluripotent stem cells. J. Clin. In Vest 125, 2551-2557. doi: 10.1172/JCI80575

Nizzardo, M., Simone, C., Rizzo, F., Ruggieri, M., Salani, S., Riboldi, G., et al. (2014). Minimally invasive transplantation of iPSC-derived ALDHhiSSCloVLA4+ neural stem cells effectively improves the phenotype of an amyotrophic lateral sclerosis model. Hum. Mol. Genet. 23, 342-354. doi: 10. $1093 / \mathrm{hmg} / \mathrm{ddt} 425$

Okano, S., and Shiba, Y. (2019). Therapeutic potential of pluripotent stem cells for cardiac repair after myocardial infarction. Biol. Pharma Ceut. Bull. 42, 524-530. doi: 10.1248/bpb.b18-00257

Oliveira, P. H., da Silva, C. L., and Cabral, J. M. S. (2014). Concise review: ge-nomic instability in human stem cells: current status and future challeng-es. Stem Cells 32, 2824-2832. doi: 10.1002/stem.1796

Patil, M., Henderson, J., Luong, H., Annamalai, D., Sreejit, G., and Krishnamurthy, P. (2019). The art of intercellular wireless communications: exosomes in heart disease and therapy. Front. Cell Dev. Biol. 7:315. doi: 10.3389/fcell.2019. 00315

Perin, E. C., Borow, K. M., Silva, G. V., DeMaria, A. N., Marroquin, O. C., Huang, P. P., et al. (2015). A Phase II dose-escalation study of allogeneic mesenchymal precursor cells in patients with ischemic or nonischemic heart failurenovelty and significance. Circ. Res. 117, 576-584. doi: 10.1161/CIRCRESAHA.115. 306332

Priest, C. A., Manley, N. C., Denham, J., Wirth, E. D., and Lebkowski, J. S. (2015). Preclinical safety of human embryonic stem cell-derived oligodendrocyte progenitors supporting clinical trials in spinal cord injury. Regen. Med. 10, 939-958. doi: 10.2217/rme.15.57

Ratajczak, J., Miekus, K., Kucia, M., Zhang, J., Reca, R., Dvorak, P., et al. (2006). Embryonic stem cell-derived microvesicles reprogram hematopoietic progenitors: evidence for horizontal transfer of mRNA and protein deliv-ery. Leukemia 20, 847-856. doi: 10.1038/sj.leu.2404132 
Riegler, J., Tiburcy, M., Ebert, A., Tzatzalos, E., Raaz, U., Abilez, O. J., et al. (2015). Human engineered heart muscles engraft and survive long term in a rodent myocardial infarction model. Circ. Res. 117, 720-730. doi: 10.1161/ CIRCRESAHA.115.306985

Rogers, R. G., Fournier, M., Sanchez, L., Ibrahim, A. G., Aminzadeh, M. A., Lewis, M. I., et al. (2019). Disease-modifying bioactivity of intravenous cardiospherederived cells and exosomes in mdx mice. JCI Insight 4:e125754. doi: 10.1172/jci. insight. 125754

Romagnuolo, R., Masoudpour, H., Porta-Sánchez, A., Qiang, B., Barry, J., Laskary, A., et al. (2019). Human embryonic stem cell-derived cardiomy-ocytes regenerate the infarcted pig heart but induce ventricular tach-yarrhythmias. Stem Cell Rep. 12, 967-981. doi: 10.1016/j.stemcr.2019.04.005

Sackstein, R. (2009). Glycosyltransferase-programmed stereosubstitution (GPS) to create HCELL: engineering a roadmap for cell migration. Immunol. Rev. 230, 51-74. doi: 10.1111/j.1600-065X.2009.00792.x

Sadek, H., and Olson, E. N. (2020). Toward the goal of human heart regenera-tion. Cell Stem Cell 26, 7-16. doi: 10.1016/j.stem.2019.12.004

Santoso, M. R., Ikeda, G., Tada, Y., Jung, J., Vaskova, E., Sierra, R. G., et al. (2020). Exosomes from induced pluripotent stem cell-derived cardio-myocytes promote autophagy for myocardial repair. J. Am. Heart Assoc. 9:e014345. doi: 10.1161/JAHA.119.014345

Sato, Y., Bando, H., Di Piazza, M., Gowing, G., Herberts, C., Jackman, S., et al. (2019). Tumorigenicity assessment of cell therapy products: the need for global consensus and points to consider. Cytotherapy 21, 1095-1111. doi: 10.1016/j. jcyt.2019.10.001

Schwach, V., Gomes Fernandes, M., Maas, S., Gerhardt, S., Tsonaka, R., van der Weerd, L., et al. (2020). Expandable human cardiovascular progenitors from stem cells for regenerating mouse heart after myocardial infarction. Cardiovasc. Res. 116, 545-553. doi: 10.1093/cvr/cvz181

Shao, L., Zhang, Y., Lan, B., Wang, J., Zhang, Z., Zhang, L., et al. (2017). MiRNAsequence indicates that mesenchymal stem cells and exosomes have similar mechanism to enhance cardiac repair. BioMed Res. Int. 2017, 1-9. doi: 10.1155/ 2017/4150705

Sharma, S., Mishra, R., Bigham, G. E., Wehman, B., Khan, M. M., Xu, H., et al. (2017). A deep proteome analysis identifies the complete secretome as the functional unit of human cardiac progenitor cells. Circ. Res. 120, 816-834. doi: 10.1161/CIRCRESAHA.116.309782

Shiba, Y., Gomibuchi, T., Seto, T., Wada, Y., Ichimura, H., Tanaka, Y., et al. (2016). Allogeneic transplantation of iPS cell-derived cardiomyocytes regenerates primate hearts. Nature 538, 388-391. doi: 10.1038/nature 19815

Singla, D. K., Ahmed, A., Singla, R., and Yan, B. (2012). Embryonic stem cells improve cardiac function in doxorubicin-induced cardiomyopathy mediated through multiple mechanisms. Cell Transplant 21, 1919-1930. doi: 10.3727/ 096368911 X627552

Smith, R. R., Barile, L., Cho, H. C., Leppo, M. K., Hare, J. M., Messina, E., et al. (2007). Regenerative potential of cardiosphere-derived cells expanded from percutaneous endomyocardial biopsy specimens. Circulation 115, 896-908. doi: 10.1161/CIRCULATIONAHA.106.655209

Sun, X., Shan, A., Wei, Z., and Xu, B. (2018). Intravenous mesenchymal stem cell-derived exosomes ameliorate myocardial inflammation in the dilated cardiomyopathy. Biochem. Biophys. Res. Commun. 503, 2611-2618. doi: 10. 1016/j.bbrc.2018.08.012

Tang, C., Lee, A. S., Volkmer, J.-P., Sahoo, D., Nag, D., Mosley, A. R., et al. (2011). An antibody against SSEA-5 glycan on human pluripotent stem cells enables removal of teratoma-forming cells. Nat. Biotechnol. 29, 829-834. doi: $10.1038 /$ nbt.1947

Tang, X.-L., Nakamura, S., Li, Q., Wysoczynski, M., Gumpert, A. M., Wu, W.-J., et al. (2018). Repeated administrations of cardiac progenitor cells are superior to a single administration of an equivalent cumulative dose. J Am Heart Assoc. 7:e007400. doi: 10.1161/JAHA.117.007400

Taylor, M., Jefferies, J., Byrne, B., Lima, J., Ambale-Venkatesh, B., Ostovaneh, M. R., et al. (2019). Cardiac and skeletal muscle effects in the randomized HOPE-Duchenne trial. Neurology 92, e866-e878. doi: 10.1212/WNL. 0000000000006950

Théry, C., Witwer, K. W., Aikawa, E., Alcaraz, M. J., Anderson, J. D., Andriantsitohaina, R., et al. (2018). Minimal information for studies of extra-cellular vesicles 2018 (MISEV2018): a position statement of the Interna-tional society for extracellular vesicles and update of the MISEV2014 guidelines. J. Extracell. Vesicles 7:1535750. doi: 10.1080/20013078.2018.1535750

Tiburcy, M., Hudson, J. E., Balfanz, P., Schlick, S., Meyer, T., Chang Liao, M.-L., et al. (2017). Defined engineered human myocardium with advanced maturation for applications in heart failure modeling and repair. Cir Culation 135, 1832-1847. doi: 10.1161/CIRCULATIONAHA.116.02 4145

Timmers, L., Lim, S. K., Hoefer, I. E., Arslan, F., Lai, R. C., van Oorschot, A. A. M., et al. (2011). Human mesenchymal stem cell-conditioned medium improves cardiac function following myocardial infarction. Stem Cell Res. 6, 206-214. doi: 10.1016/j.scr.2011.01.001

van Berlo, J. H., Kanisicak, O., Maillet, M., Vagnozzi, R. J., Karch, J., Lin, S.-C. J., et al. (2014). c-kit+ cells minimally contribute cardiomyocytes to the heart. Nature 509, 337-341. doi: 10.1038/nature13309

van Laake, L. W., Passier, R., den Ouden, K., Schreurs, C., Monshouwer-Kloots, J., Ward-van Oostwaard, D., et al. (2009). Improvement of mouse cardiac function by hESC-derived cardiomyocytes correlates with vascularity but not graft size. Stem Cell Res. 3, 106-112. doi: 10.1016/j.scr.2009.05.004

van Laake, L. W., Passier, R., Monshouwer-Kloots, J., Verkleij, A. J., Lips, D. J., Freund, C., et al. (2007). Human embryonic stem cell-derived cardiomy-ocytes survive and mature in the mouse heart and transiently improve function after myocardial infarction. Stem Cell Res 1, 9-24. doi: 10.1016/j.scr.2007. 06.001

Vandergriff, A., Huang, K., Shen, D., Hu, S., Hensley, M. T., Caranasos, T. G., et al. (2018). Targeting regenerative exosomes to myocardial infarction us-ing cardiac homing peptide. Theranostics 8, 1869-1878. doi: 10.7150/thno.20524

Vandergriff, A. C., de Andrade, J. B. M., Tang, J., Hensley, M. T., Piedrahita, J. A., Caranasos, T. G., et al. (2015). Intravenous cardiac stem cell-derived exosomes ameliorate cardiac dysfunction in doxorubicin induced dilated cardiomyopathy. Stem Cells Int. 2015, 1-8. doi: 10.1155/2015/960926

Walker, P. A., Shah, S. K., Jimenez, F., Aroom, K. R., Harting, M. T., and Cox, C. S. (2012). Bone marrow-derived stromal cell therapy for traumatic brain injury is neuroprotective via stimulation of non-neurologic organ sys-tems. Surgery 152, 790-793. doi: 10.1016/j.surg.2012.06.006

Waters, R., Alam, P., Pacelli, S., Chakravarti, A. R., Ahmed, R. P. H., and Paul, A. (2018). Stem cell-inspired secretome-rich injectable hydrogel to repair injured cardiac tissue. Acta Biomater. 69, 95-106. doi: 10.1016/j.actbio.2017.12.025

Whyte, W., Roche, E. T., Varela, C. E., Mendez, K., Islam, S., O’Neill, H., et al. (2018). Sustained release of targeted cardiac therapy with a replenishable implanted epicardial reservoir. Nat. Biomed. Eng. 2, 416-428. doi: 10.1038/ s41551-018-0247-5

Wiklander, O. P. B., Brennan, M. Á, Lötvall, J., Breakefield, X. O., and El An-daloussi, S. (2019). Advances in therapeutic applications of extracellular vesicles. Sci. Transl. Med. 11:eaav8521. doi: 10.1126/scitranslmed.aav8521

Wiklander, O. P. B., Nordin, J. Z., O’Loughlin, A., Gustafsson, Y., Corso, G., Mäger, I., et al. (2015). Extracellular vesicle in vivo biodistribution is de-termined by cell source, route of administration and targeting. J. Extracell Vesicles 4:26316.

Wysoczynski, M., and Bolli, R. (2020). A realistic appraisal of the use of embryonic stem cell-based therapies for cardiac repair. Eur. Heart J. 41, 2397-2404. doi: 10.1093/eurheartj/ehz787

Xu, H., Wang, B., Ono, M., Kagita, A., Fujii, K., Sasakawa, N., et al. (2019). Targeted Disruption of HLA Genes via CRISPR-Cas9 Generates iPSCs with Enhanced Immune Compatibility. Cell Stem Cell 24, 566.e1-578.e1. doi: 10.1016/j.stem. 2019.02.005

Xu, R., Zhang, F., Chai, R., Zhou, W., Hu, M., Liu, B., et al. (2019). Exosomes derived from pro-inflammatory bone marrow-derived mesenchymal stem cells reduce inflammation and myocardial injury via mediating macrophage polarization. J. Cell. Mol. Med. 23, 7617-7631. doi: 10.1111/jcmm.14635

Yarbrough, W. (2003). Large animal models of congestive heart failure: a critical step in translating basic observations into clinical applications. J. Nucl. Cardiol. 10, 77-86. doi: 10.1067/mnc.2003.16

Ye, J., Gaur, M., Zhang, Y., Sievers, R. E., Woods, B. J., Aurigui, J., et al. (2015). Treatment with hESC-derived myocardial precursors improves cardiac function after a myocardial infarction. PLoS One 10:e0131123. doi: 10.1371/ journal.pone.0131123

Yee, K., Malliaras, K., Kanazawa, H., Tseliou, E., Cheng, K., Luthringer, D. J., et al. (2014). Allogeneic cardiospheres delivered via percutaneous transen-docardial injection increase viable myocardium, decrease scar size, and attenuate cardiac 
dilatation in porcine ischemic cardiomyopathy. PLoS One 9:e113805. doi: 10. 1371/journal.pone. 0113805

Yin, J. Q., Zhu, J., and Ankrum, J. A. (2019). Manufacturing of primed mesenchymal stromal cells for therapy. Nat. Biomed. Eng. 3, 90-104. doi: 10.1038/ s41551-018-0325-8

Yoshida, S., Miyagawa, S., Toyofuku, T., Fukushima, S., Kawamura, T., Kawamura, A., et al. (2020). Syngeneic mesenchymal stem cells reduce im-mune rejection after induced pluripotent stem cell-derived allogeneic cardiomyocyte transplantation. Sci. Rep. 10:4593. doi: 10.1038/s41598-020-58126-z

Yuan, A., Farber, E. L., Rapoport, A. L., Tejada, D., Deniskin, R., Akhmedov, N. B., et al. (2009). Transfer of microRNAs by embryonic stem cell mi-crovesicles. PLoS One 4:e4722. doi: 10.1371/journal.pone.0004722

Yuan, O., Lin, C., Wagner, J., Anderson, J. S., Archard, J. A., Deng, P., et al. (2019). Exosomes derived from human primed mesenchymal stem cells induce mitosis and potentiate growth factor secretion. Stem Cells Dev. 28, 398-409. doi: $10.1089 / \mathrm{scd} .2018 .0200$

Zhao, J., Li, X., Hu, J., Chen, F., Qiao, S., Sun, X., et al. (2019). Mesenchymal stromal cell-derived exosomes attenuate myocardial ischaemia-reperfusion injury through miR-182-regulated macrophage polarization. Cardiovasc. Res. 115, 1205-1216. doi: 10.1093/cvr/cvz040

Zhu, K., Wu, Q., Ni, C., Zhang, P., Zhong, Z., Wu, Y., et al. (2018). Lack of Re-muscularization following transplantation of human embryonic stem cell-derived cardiovascular progenitor cells in infarcted nonhuman primates. Circ. Res. 122, 958-969. doi: 10.1161/CIRCRESAHA.117. 311578

Conflict of Interest: The author declares that the research was conducted in the absence of any commercial or financial relationships that could be construed as a potential conflict of interest.

Copyright (c) 2020 Menasché. This is an open-access article distributed under the terms of the Creative Commons Attribution License (CC BY). The use, distribution or reproduction in other forums is permitted, provided the original author(s) and the copyright owner(s) are credited and that the original publication in this journal is cited, in accordance with accepted academic practice. No use, distribution or reproduction is permitted which does not comply with these terms. 